Note

\section{Aroma Components of Fresh Sugar Cane Juice}

\section{Yukiko ToKitomo, Akio KobAYASH* and Tei YAMANISHI*}

Nagoya Junior College, Toyoake, Aichi 470-11, Japan * Laboratory of Food Chemistry, Ochanomizu University, Bunkyo-ku, Tokyo 112, Japan

Received May 29, 1984

In previous papers, ${ }^{1 \sim 3)}$ we have reported the compounds responsible for the sugary flavor of raw cane sugar. Many aroma components have been identified from cane molasses, and the most important key compound of the sugary flavor was identified to be 3-hydroxy-4,5dimethyl-2(5H)-furanone (sotolon). ${ }^{3)}$ 4-Hydroxy-3methoxybenzaldehyde (vanillin), 3-hydroxy-2-methyl-4pyranone, 2-hydroxy-3-methyl-2-cyclopentenone, 4-nonanolide, 4-vinylphenol, and 2,6-dimethoxyphenol were also thought to contribute to the sugary flavor. These aroma components seemed to be a mixture of naturally occurring products of sugar cane and by-products arising during raw cane sugar manufacturing with a high temperature $\left(105^{\circ} \mathrm{C}\right)$ and akaline conditions. We investigated the aroma components of fresh juice from sugar cane and compared them with those of cane molasses to estimate the formation of the sugary flavor. For extraction, fractionation, and identification of aroma components of cane juice we followed the same procedures as for cane molasses. ${ }^{1,3)}$

The cane juice was produced from cane (Saccharum officinarum var. NCO 376) in Nago, Okinawa, harvested in January, 1979. Without heating and adding lime, the juice was already dark green and had a characteristic sweet aroma like that of brown sugar with a green note.

The juice $(11.6 \mathrm{~kg})$ was extracted with ether continuously using liquid-liquid extracting apparatus for $40 \mathrm{hr}$, and $5.42 \mathrm{~g}(0.047 \%)$ of aroma concentrate with a green and sugary odor was obtained. The aroma concentrate $(4.0 \mathrm{~g})$ was separated by silica-gel column chromatography as shown in Table I. The most characteristic aroma existed in fraction 11 (Fr. 11), which was further separated by preparative gas chromatography using a Shimadzu GC-4A gas chromatograph equipped with a thermal conductivity detector. By sniffing the GC effluents, smoky and slightly sugary aromas were found concentrated between retention times of 53 and $65 \mathrm{~min}$ (column, $10 \%$ SP2100 on 100/120 Chromosorb AW-DMCS; glass packed column $3 \mathrm{~m} \times$ $4 \mathrm{~mm}$ i.d.; column temp., programmed from 70 to $180^{\circ} \mathrm{C}$, at a rate of $2^{\circ} \mathrm{C} / \mathrm{min}$ ). This fraction was trapped (Fr. 11trap) and was rechromatographed with a Shimadzu GC$6 \mathrm{~A}$ gas chromatograph equipped with a flame ionization detector and glass SCOT column as described in Fig. 1. Identification of the individual peaks was performed by matching of their mass spectra and their GC retention times with those of authentic samples. GC-MS spectra were recorded with a Hitachi RMU-6MG mass spectrometer combined with a Hitachi 063 gas chromato-

Table I. Fractionation of the Aroma Concentrate (4.0 g) by Silica-gel

COLUMN* Chromatography

\begin{tabular}{|c|c|c|c|c|c|c|}
\hline \multirow{2}{*}{ Fraction } & \multicolumn{3}{|c|}{ Solvent } & \multirow{2}{*}{$\begin{array}{l}\text { Volume } \\
(\mathrm{ml})\end{array}$} & \multirow{2}{*}{$\begin{array}{l}\text { Yield } \\
(\mathrm{g})\end{array}$} & \multirow{2}{*}{ Aroma } \\
\hline & Benzene- & -Ethyl acetate & -Methanol & & & \\
\hline 1 & 100 & & & 100 & 0 & Inodorous \\
\hline 2 & 100 & & & 100 & 0.57 & Rubber-like \\
\hline 3 & 100 & 1 & & 100 & 0.46 & Fruity \\
\hline 4 & 50 & 1 & & 100 & 0.51 & Phenolic \\
\hline 5 & 25 & 1 & & 60 & 0.13 & Inodorous \\
\hline 6 & 15 & 1 & & 60 & 0.06 & Medicinal \\
\hline 7 & 8 & 1 & & 80 & 0.17 & Medicinal, floral \\
\hline 8 & 4 & 1 & & 60 & 0.23 & Phenolic \\
\hline 9 & 4 & 1 & & 75 & 0.23 & Sweet, green \\
\hline 10 & 2 & 1 & & 75 & 0.35 & Green, sugary \\
\hline 11 & 1 & 1 & & 80 & 0.18 & Sweet, sugary \\
\hline 12 & & 100 & & 80 & 0.17 & Acidic, green \\
\hline 13 & & 100 & & 110 & 0.32 & Acidic, sweet \\
\hline 14 & & 50 & 1 & 60 & $0.12)$ & \\
\hline 15 & & 10 & $: \quad 1$ & 50 & $0.12\}$ & Inodorous \\
\hline 16 & & 1 & $: \quad 1$ & 50 & $0 \quad J$ & \\
\hline
\end{tabular}

* Column: $2.4 \mathrm{~cm}$ (i.d.) $\times 56 \mathrm{~cm}$, Wakogel C-200, $70 \mathrm{~g}$. 


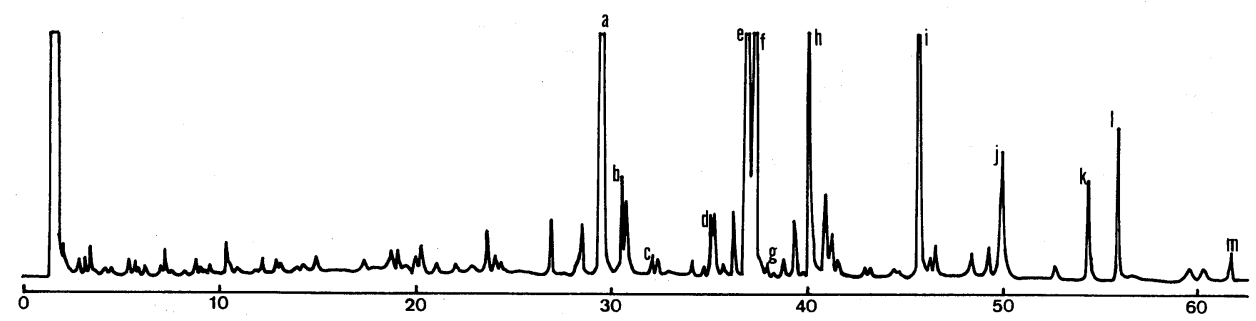

FIG. 1. Gas Chromatogram of Fr. 11-Trap.

Analytical conditions: Column, $30 \mathrm{~m} \times 0.28 \mathrm{~mm}$ i.d. glass SCOT column coated with FFAP; column temp., programmed from $70^{\circ} \mathrm{C}$ to $180^{\circ} \mathrm{C}$ at a rate of $2^{\circ} \mathrm{C} / \mathrm{min}$; temp. of injector and detector, $190^{\circ} \mathrm{C}$; carrier gas, nitrogen; flow rate of $1.2 \mathrm{ml} / \mathrm{min}$ at column inlet.

Identified peaks: a), hexanoic acid and 2-methoxyphenol; b), benzyl alcohol; c), 2-phenylethanol; d), heptanoic acid; e) phenol; f), 4-nonanolide; g), 3-phenyl-1-propanol; h) nonanoic acid; i), 4-hydroxy-3methoxystyrene; j), 3-phenyl-2-propenol; k), 4-vinylphenol; 1), phthalate (contaminant); m), 4-hydroxy-2methoxybenzaldehyde.

graph. The column was a $30 \mathrm{~m} \times 0.28 \mathrm{~mm}$ i.d. glass SCOT column coated with Thermon $600 \mathrm{~T}$ and the oven temperature was programmed from 70 to $220^{\circ} \mathrm{C}$ at a rate of $3^{\circ} \mathrm{C} / \mathrm{min}$. The ionization energy was $20 \mathrm{eV}$.

As shown in Fig. 1, the main components of the Fr. 11-trap, a), b), c), e), f), i), k), and m) were also identified in cane molasses, among which 4-nonanolide, 4-vinylphenol, and 4-hydroxy-3-methoxybenzaldehyde were considered to contribute to the sugary aroma of this fraction. Therefore, these phenolic compounds and lactone originate from raw cane juice and contribute to the sugary aroma.

On the other hand, the other sugary flavor components, 3-hydroxy-2-methyl-4-pyranone ${ }^{3,4)}$ and 2-hydroxy-3methyl-2-cyclopentenone, ${ }^{1)}$ could not be found in fresh cane juice and these typical volatile products were assumed to be formed from sugar by heating. ${ }^{5}$

Sotolon could not be identified in cane juice. Two of the authors claimed in another paper ${ }^{6)}$ that sotolon was prepared by condensation of pyruvate and 2-oxobutyrate, 2-oxoglutarate, or glutamate which exist in cane juice under the same conditions as those used in raw cane sugar manufacturing. The present result also supports the formation of this key compound of the sugary flavor during sugar processing, but the presence of sotolon in fresh cane juice is still undeniable because the odor threshold value of sotolon is very low $(0.01 \mathrm{ppb}$ in water $)$ and the characteristic aroma of Fr. 11-trap could not be regenerated by mixing the identified compounds. The identification of minor components of this aroma are now in progress using a large quantity of fresh cane juice with more sophisticated techniques.

Acknowledgments. We wish to thank Dr. Y. Nakasone of Ryukyu University and the Hokubu Sugar Corporation in Nago for kindly supplying the cane juice. We are also indebted to Dr. S. Muraki, Takasago Perfumary Co., Ltd., for obtaining the mass spectra by capillary GC-MS. We express special appreciation to the late Professor S. Takei for his valuable advice and encouragement.

\section{REFERENCES}

1) E. Abe, Y. Nakatani, T. Yamanishi and S. Muraki, Proc. Jpn. Acad., 54B, 542 (1978).

2) Y. Tokitomo, A. Kobayashi, T. Yamanishi and S. Muraki, Proc. Jpn. Acad., 56B, 452 (1980).

3) Y. Tokitomo, A. Kobayashi, T. Yamanishi and S. Muraki, Proc. Jpn. Acad., 56B, 457 (1980).

4) H. Ito, Agric. Biol. Chem., 40, 827 (1976).

5) R. R. Johnson, E. D. Alford and G. W. Kinzer, $J$. Agric. Food Chem., 22, 17 (1969).

6) M. Nose, A. Kobayashi, T. Yamanishi, M. Matsui and S. Takei, Nippon Nôgeikagaku Kaishi, 57, 557 (1983). 